\title{
Joyce Goggin
}

University of Amsterdam, Netherlands

\begin{abstract}
Scholarship on the finance-security nexus has typically been concerned with 'first order' phenomena, such as the interpenetration of the finance and security sectors. This article contributes to the debate by turning to an apparent epiphenomenon, namely The LEGO Movie, and using it to address some overlooked intersections between popular culture and the finance-security complex. The analysis first focuses on how finance and security are represented in the film, through the plot and the fictional company at the centre of the film's conflict, to its LEGO minifigure characters and the playsets featured therein. The focus then shifts to how the LEGO Group's business model informs the film in significant ways, from the plot's motivation and structure, and the mise-en-scène, to how the film was produced. My argument throughout is that a seemingly innocent or insignificant film in fact participates in the financialization and securitization of daily life through its very style and status as a cultural product. Key here is how The LEGO Movie does this in ways that confound possible critique through the use of irony and cute aesthetics, as well as through its own supposed triviality.
\end{abstract}

\section{Keywords}

LEGO, affect, finance, securitization, creativity, surveillance

\section{Introduction}

Utram bibis? Aquam an undam? - What are you drinking? The Water or the Wave?

John Fowles, The Magus

The longstanding relationship between security and finance has been discussed in various disciplines (international political economy, political science, geography, security studies, international relations) and from a variety of perspectives (military, geopolitical, corporate, historical, and so on) (see Amicelle, 2011; Amoore, 2011; Boy, 2015; de Goede, 2010;

\section{Corresponding author:}

Joyce Goggin, University of Amsterdam, Spuistraat 134, Kamer 526, 1012 VB Amsterdam, Netherlands.

Email: j.goggin@uva.nl 
Langley, 2010; Lightfoot and Lilley, 2017; Lobo-Guerrero, 2011; Martin, 2007, 2015; Taylor, 2004; Vogl, 2017). In this article, I want to draw from these discussions in order to explore one particular case study, namely The LEGO Movie (where both plot and production are concerned) and to unpack the ways in which it presents, in a comic, seemingly anodyne fashion, some of the troubling aspects of how finance and security intersect. In what follows, I will frame The LEGO Movie as a representation of this intersection, as well as a film that one would intuitively associate with children, pure entertainment, and light-hearted comedy. In so doing, I will demonstrate how this film, somewhat counter-intuitively, remediates urgent issues in ways both obvious and metaphorical, and speaks to how various aspects of our daily lives have become financialized and securitized through channels that are easily overlooked. ${ }^{1}$

Before drilling down into the bedrock of my argument, I want to offer two examples of what I mean by 'obvious' and 'metaphorical'. First, at the surface level of the plot and the obvious, the film features a ludic universe controlled by President Business of Octan, a massive corporation that produces "music, dairy products, coffee, TV shows ... surveillance systems, all history books, [and] voting machines". ${ }^{2}$ The central plot driver of the movie is thus a large financialized and highly diversified corporation that specializes in surveillance equipment, while the company's president is also the political leader of the film's fictional universe. In my reading therefore, I will address this movie as exemplifying the practice of preserving or securing the financial system (i.e., Octan) by getting rid of "threats to the existing economic order" such that, by virtue of the story line alone, The LEGO Movie is a good example of how a corporate government might use surveillance in order to securitize the economic order, and by extension, the despotic political order (Amicelle, 2011: 162).

Where metaphor is concerned, those who have seen The LEGO Movie will recall that the mise-en-scène digitally reproduces the look and feel of amateur stop-animation films produced by LEGO fans and this, of course, is a large part of the film's aesthetic texture and charm. More specifically, in a scene wherein the heroes find themselves adrift at sea, viewers are treated to the mesmerizing spectacle of enormous waves on which the LEGO minifigure heroes are tossed, momentarily suspended, and tossed again. The fascination of this scene resides, at least to my mind, in watching these waves that, due to the constraints or affordances of simulating the effects of stop-animation, appear to be both solid and liquid at turns. I want to suggest, then, that this method of recreating the look of liquid movement in stops and starts serves as a compelling and oddly accurate visual metaphor for some of the arguments I will make here. This is to say that, in order to create the illusion of liquidity and continuous movement (albeit in a digital medium that only mimics stop-motion), the bricks that make up the waves have to be stabilized momentarily before they are destabilized and move forward. Or, put differently, the visual effect of the stop-motion wave is produced in ways analogous to attempting to securitize the financial order through the introduction of "spectacular in-security in economic life", or by supposedly stabilizing the financial order through the introduction of multiple insecurities necessitated by the drive to capitalize on instability and risk (de Goede, 2010: 104, 106). Hence, in this reading, the illusion of liquidity created in the film will be understood as a metaphor for how liquidity is created and secured in finance (Langley, 2015). Likewise, this movement will be further understood as crystallizing or expressing, in a particularly direct and compelling way, the logic of security and finance built into the LEGO system itself, from the uniformity of the bricks and the interchangeability that subtends the product's logic, to the plot, and the LEGO Group; both its business model and the ways in which the company and the movie attempt to securitize or shore up against risk.

The article will, therefore, involve unpacking various aspects of The LEGO Movie such as the plot, as well as details like the waves just mentioned, in light of the arguments I have just 
sketched out. This will be undertaken in order to demonstrate how the film and the LEGO company work to subtly guide viewers and consumers towards implicitly or explicitly accepting and understanding these 'waves', or disaggregated features of the finance-security complex, and towards accepting the greater ocean of factors that inform our daily lives and shape us as subjects. Put differently, I take the dynamism that underlies stop-motion cinema and the way in which the wave works and is depicted in The LEGO Movie as a metaphor for the greater economy, particularly on the point of security and finance. And, to pursue the analogy I am attempting to draw between my argument and the epigraph for this article - What are you drinking? The water or the wave? - I will take the waves, rendered in CGI LEGO bricks, as well as The LEGO Movie itself, as constituents of a much larger, non-trivial body of systems and assemblages that inform our daily lives. The film will then be read as a wave, that is, as an element of a vast seascape of politics and finance that we are compelled, coerced, or entertained into 'drinking in' as the naturalized vista of our contemporary life worlds.

\section{The plot: One brick at a time}

In order to pursue the argument just outlined, I will briefly synopsize the plot of The LEGO Movie and the film's central conflict, which revolves around a group of minifigures fighting for their freedom by attempting to subvert the constant surveillance to which they are subjected under the Octan corporation and its leader, President (aka Lord) Business (Will Ferrell), Tyrant of Bricksburg and the LEGO Universe. The minifigures are never permitted to forget that they are being watched through notices posted everywhere in Bricksburg, including enormous billboards that carry slogans like "Conform, it's the Norm" and "President Business: "Because I said so'". This ubiquitous signage is reinforced with constant live public messages from Lord Business, such as "Let's take extra care to follow the instructions (or be put to sleep)", blasted out on media all over Bricksburg. The minifigures are also made aware that uninterrupted vigilance and defensive reporting is required of them, through frequent reminders to "report anything weird" or "blow it up" immediately.

In exchange for their unflagging loyalty, a public announcement is made that the workers of Bricksburg will be treated to a free taco served with President Business' love on a celebratory fun day, which he has dubbed "Taco Tuesday". This is, of course, a thinly disguised plot devised by Lord Business who, with the help of his Micro-Managers, plans to cement the LEGO universe permanently in place on that special Tuesday with "Kragle", a superweapon that is in reality a tube of Krazy Glue on which the " $z$ ", the " $y$ ", and the "u" have worn off. So, although President Business tells his employees that everyone will get a free treat and his love on Taco Tuesday, the viewer is made privy to the knowledge that "Taco" is really spelled T.A.K.O.S., wherein "the 's' is silent", and wherein the other letters stand for "Tentacle Arm Kragle Outside Sprayer". And, because Lord Business' superweapon is guarded the top of the Octan tower on the "infinity-ieth floor" with "every kind of security measure imaginable", stopping the evil plan presents a formidable challenge.

It is Emmet who, however unwittingly, becomes tasked with thwarting President Business when he happens upon Wyldstyle (Elizabeth Banks), a female minifigure whom he finds poking around on his construction site. As he goes to investigate, Emmet falls into a hole and onto the missing cap to Lord Business' Kragle, known to Wyldstyle and the Bricksburg freedom fighters as the "Piece of Resistance", and the only thing that can prevent President Business's plan to end the world on "Taco Tuesday". The glue cap, which becomes stuck to Emmet's back, causes him to lapse into a hallucinatory state from which he awakens in the custody of 
President Business' bipolar assistant, Lieutenant Bad Cop/Good Cop (Liam Neeson). Wyldstyle rescues Emmet and takes him on a journey through LEGO playsets on their way to meeting Vitruvius (Morgan Freeman), a wizard who prophesizes that a person to be known as "The Special" will find the Piece of Resistance and put an end to Lord Business' evil plans. With this new role thrust upon him, Emmet becomes known as "the most talented, most interesting, and most extraordinary person in the universe", and goes on a predictable, blockbuster quest to live up to his calling.

\section{Intersections: LEGO, finance, security}

This outline of the central conflict that drives The LEGO Movie has hopefully illustrated how the whimsicality of various amusing and cute features of the plot serve as a thin veneer that barely obscures a number of similarities with the current real-world situation, not the least of which is the uncanny resemblance that the film's President Business bears to $45^{\text {th }}$ President of the United States.

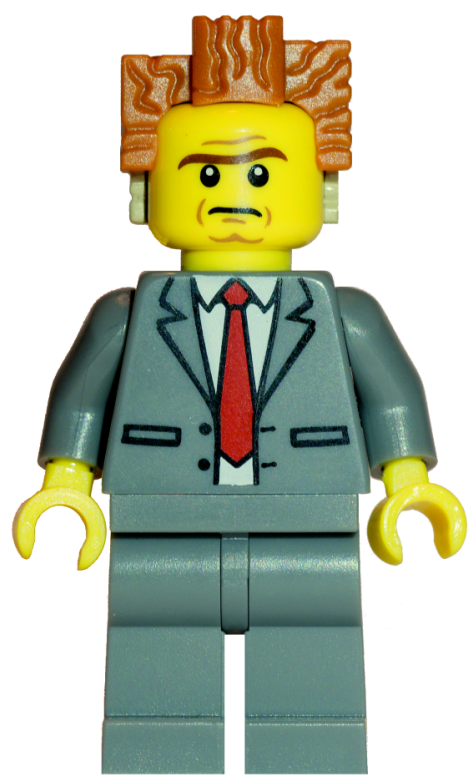

Figure 1. Minifigure of President (aka 'Lord') Business. Photography credit: Dries Arnolds.

Other details of the Bricksburg toy universe likewise recall aspects of our own, such as Octan, the highly diversified company at the heart of the drama for which all of the minifigures work, and which itself is reminiscent of Big Ten companies like Nestlé and Unilever. Octan's nefarious, if diversified, activities are revealed in moments of self-conscious irony throughout the film, such as when Bruce Wayne of Wayne Enterprises' tells Lord Business, "We'd like to invest in your company. Your weapon to control the universe sounds super sweet". Here then, viewers catch a glimpse of how finance (i.e., investment) and security (i.e., a "weapon to control the universe") are entangled, in barely a second of this fast-paced film's screen time.

For some, Octan's role in the manufacture of surveillance systems, and its pointed mention in the film, may bring to mind various sources on this topic, such as the chapter of Naomi Klein's (2007: 281-323) The Shock Doctrine, in which she discusses the profitability of security industries and products post 9/11. Here she explains how, following the 9/11 attack on the Twin Towers, close ties were forged between finance and security, with the result that 
surveillance equipment emerged as a major industry. As she points out, "one of the first booms for the homeland security industry was surveillance cameras, 4.2 million of which have been installed in Britain [...] and 30 million in the U.S." (Klein, 2007: 302). Given Klein's observations, or the more generalized knowledge that increased post-9/11 security in many countries around the globe has become a booming industry, the film's unabashed announcement that the "good stuff" made by Octan includes surveillance cameras, as well as voting machines and all history books, should raise a flag in the minds of viewers. This is echoed in Emmet's own interjection of "wait a minute" after rattling off the list of Octan's premier products (i.e., "music, dairy products, coffee, TV shows ... surveillance systems, all history books, voting machines").

Moreover, where the broader context of scholarship on finance and security is concerned, one is also reminded of Marieke de Goede's (2010: 100) discussion of instrumentality as one aspect of how finance and security are interrelated, whereby "finance is deployed in the service of security" - that is, as an instrument for the securitization of the state. ${ }^{3}$ This has its parallel in Octan of The LEGO Movie, a company that deals in surveillance technology, while stringently regulating Bricksburg's "rule-following citizens" who maximize Octan's profits. The company's profitable continuance is secured, as noted, by keeping its workers under constant surveillance, while profits flow directly into Lord Business' "super sweet" weapon to control the universe. The movie therefore comically reiterates the long tradition of finance underwriting the securitization of the state in numerous ways such as funding wars, or refinancing royal debt beginning in the seventeenth century, and which would now include banking policy, derivatives, and other financial instruments (Boy, 2015; Vogl, 2017; de Goede, 2010). And indeed, here the relationship between the two is in full view: the sustained financial success of Octan equals controlling the universe.

Introduced in numerous ways in The LEGO Movie, the pressure that state control exerts over freedoms large and small is connected to virtually every feature of the plot, and has a certain amount of resonance where LEGO's own real-life business model is concerned. This is to say that, since 1955 and the release of "Town Plan", LEGO has been "kragling" their bricks into controlled play systems marketed with instructions for correct, scripted play. Indeed, it was only in response to complaints from fans that loose bricks are hard to come by, and from artist Ai Weiwei who needed loose bricks to complete a sculpture, that the company began occasionally marketing buckets of bricks not specifically intended for play systems. ${ }^{4}$ However, one such issue, "Creative Bucket 10662", advertised as offering "a world of unlimited building fun" also comes, ironically enough, with instructions for specific scenarios and themes.

More pointedly, the kind of thinking behind play systems, buckets and bricks also applies to The LEGO Movie's plot, which is similarly constructed around what Julie Sanders (2006: 63) refers to as "mythic templates and outlines [for] storytelling", that are "persistently relocated in [...] new cultural geograph[ies] at each occasion of adaptation". So, on the one hand, the minifigures' cinematic quest is undertaken to insure their "free[dom] to travel and mingle, and build whatever they want", as they supposedly did before President Business "erected walls between worlds and became obsessed with order", compelling the minifigures to "follow the rules" and "make everything look like it does in the instructions". On the other hand, however, The LEGO Movie, like the boxed playsets, exploits rigid, interchangeable storytelling templates such as Outer Space or the Old West, so that the story ends up reproducing any number of typical, predictable, affect-producing scenarios. The story templates then, like the "creativity bucket" and other play systems, fall short of the mark of providing unbridled creativity, hence the freedoms afforded players and viewers are shallow and partial at best. The irony here then consists in holding out something like Derridean 'free play', while actually offering controlled 
and set parameters for play, which are inscribed in LEGO's technical make-up along with "rules and requirements embedded into the design that promote specific user behavior" (Lauwaert, 2009: 13). ${ }^{5}$

On a macro signifying scale, the film follows the logic of a market in which it is essential to secure profits by addressing and pleasing as many viewers as possible. It offers multiple points of entry for various audience segments, including children and AFOLs [Adult Fans of LEGO], as well as viewers familiar with other storyworlds presented in the film, such as Batman, Star Wars and so on. The LEGO Movie also short-circuits obvious critiques while placating viewers who may be skeptical about the film's uplifting creativity message. This is accomplished through self-conscious humour that makes fun of transmedia storytelling while building on formulaic, interchangeable templates, delivered in a film whose core purpose is market expansion. Moreover, given that modern media companies - like those that produced The LEGO Movie - are, as Henry Jenkins has explained, "horizontally integrated [and] hold interests across a range of what were once distinct media industries", media conglomerates have "an incentive to spread [their] brand[s] or expand [their] franchises across as many different media platforms as possible" (Jenkins, 2007: point 2). This is achieved, at least in part, by maintaining a firm grip on the franchise and policing its limits so that building "whatever weird thing pops into" the characters' minds in the film, or those of children playing with LEGO, for example, isn't possible.

\section{Freedom of movement}

The film's freedom-to-create message is intimately connected with the minifigures' somewhat self-defeating struggle to regain their liberty so as to be able to migrate from one potted playset scenario to the next in a world supposedly without borders. But, as Naomi Klein also pointed out, the dismantling of borders, which would presumably have been part of the kind of world order to which the minifigures would like to return, and which was "the great symbol and promise of globalization, has been replaced with the exploding industry of border surveillance, [including] optical scanning and biometric IDs" (Klein, 2007: 303). As previously noted, such surveillance equipment is an important part of Octan's industrial offering in The LEGO Movie, generating profits while supposedly "preserving the integrity of financial institutions and the financial system in its entirety", by eliminating threats to "the existing economic order" of Bricksburg (Amicelle, 2011: 162). This interrelatedness of surveillance, security, and finance is rendered in visual shorthand in a scene set in President Business' Office, located on the "infinity-ieth floor" of the Octan office tower, where Emmet's face is visible on multiple monitors as robots attempt to locate the escaped minifigure. As Robot \#1 tells President Business, they are trying to "locate the fugitive, but his face is so generic it matches every other face in [the] database". The President responds that this is "diabolical", whereupon the conversation immediately jumps to company profits and the ostensibly related topic of how "coffee sales are up", and then onto advertising for Taco Tuesday. So, while obliquely linking company profits to surveillance equipment, this brief segment is also suggestive of "complex new spaces of governing in which public and private authorities, knowledges and data base sets cooperate closely, [... and] sometimes become practically indistinguishable" (Amoore and de Goede, 2008: 7).

Moreover, the scene to which I refer depicts robots scanning items of data that can be combined as a "data derivative", that is, a "visualized risk flag or score drawn form an amalgam of disaggregated fragments of data, inferred across the gaps between data" 
(Amoore, 2011: 24). As critics have pointed out, how fragments of data are combined ultimately comes down to intuition and inference as well as prejudices on the part of those interpreting the data, "concealed in the glossy technoscientific gleam of the risk-based solution" (Amoore, 2011: 38) - or, in this case, the impressive display of technology in Octan's toy media lab. What is more, the data combined in such derivatives is not measured against a stable norm; rather, such derivatives work "with a mobile norm, a norm that is itself modulated and aleatory, governed not by normalcy and deviations but by differential curves of normality" (Amoore, 2011: 31). Oddly enough, however, Emmet Brickowski subverts Octan's highly developed surveillance technology by having a face that is too generic to scan and collect data on, that is, a face exactly like every other minifigure's in Bricksburg, and one that would indeed fit within a stable norm. The irony here, therefore, is difficult to pin down, given that all minifigures have the same face which would presumably make for stable norms from which to construct a model to be used in scanning and combining data. Here, however, the humour appears to rely on audience's (partial) understanding of how surveillance technology and data derivatives work, while anticipating their skepticism as to their reliability and effectiveness.

\section{Money, subjectivity, and financialization}

David Harvey (1991: 299) wrote that it "should be possible to consider how [...] money has formed a distinctive material basis for the rise of distinctive systems of [...] representation" just as "money and commodities are themselves the primary bearers of cultural codes". Indeed, from Marx through to Jameson (1991), scholars have argued that economic systems and here I am interested in how economic systems control and circulate money - are also possessed of their own specific cultural imprint or logic. Taking this as a given, I now want to consider the nature of money and how it shapes culture as exemplified by The LEGO Movie.

In The Philosophy of Money, published early in the twentieth century, Georg Simmel (2004: 120) famously described money as a leveler that creates commensurability between dissimilar commodities by embodying "abstract economic value". As such, money mediates exchange while transforming "desired objects into economic objects and establishes the substitutability of objects" (Simmel, 2004: 119, emphasis in original). Money, therefore, provides "the means [for one thing] to be exchangeable for something else [...] by sublimating the relativity of things", making money "similar to the forms of logic which lend themselves equally to any particular content, regardless of that content's development or combination" (Simmel, 2004: 121, 441). So, following Simmel's gloss on the role of money, one might say that money acts as a sort of Ur-LEGO form, that is, as a uniform, exchangeable equivalent that functions like the standard bricks, which also "bear", as David Harvey wrote, the cultural logic of money.

Similarly, Mark C. Taylor (2004: 60) has argued that "[s]tandardization allows money to be a unit of account [as] the condition of the possibility of a structure" so that money "retains a certain neutrality that is "completely adaptable to any use'", taking "many forms; [because] it is polymorphous [and] polyvalent", while retaining its neutrality as a medium of exchange. Here again, I would like to suggest that Taylor's observations concerning money, in its uniformity and exchangeability, could be equally applied to standard issue LEGO bricks, in order to argue for a fairly straightforward analogy between the two. Alternatively, one might equally assert that, because money acts as a neutral medium of exchange, and because it collapses difference and renders all things commensurate and exchangeable, it 'lego-ifies' our world, at least in this one sense. In other words, like money, standard LEGO bricks are uniform 
and identical, and serve as a medium through which any given building, scene or person may be rendered in interchangeable units. ${ }^{6}$

Moreover, it may seem fairly obvious that subjectivities and subject positions are constructed economically; that subjectivity is inseparable from the economy; and that the economy is integral to our position as subjects - yet in the current neo-liberal paradigm these axioms take on greater urgency (Langley, 2010). As Randy Martin (2007: 3) argued, finance, as the dominant system through which money is currently directed and created, has become "not simply [...] a form of capital but [...] a set of protocols for organizing daily life," around, for example, one's orientation to risk. Martin (2002) referred to the various structural shifts in how society is organized as the progressive 'financialization of daily life'. These shifts were abetted by the increasing freedom to self-regulate enjoyed by banks and lending institutions, with the result that finance and security now stand "in a causal relationship to one another, whereby finance [also] produces societal (in)securities" (de Goede, 2010: 101).

On the ground, the growing importance of finance capitalism, facilitated by the progressive deregulation of markets over the past several decades has also impacted on the role of large corporations. One effect has been a trend, since the 1980s, to massive downsizing and reductions in labour forces as a strategy to boost shareholder confidence as well as share prices. As shareholders' profits now "trump all other considerations" (Ehrenreich, 2009: 108), managers find that the most expedient course of action is constant restructuring, layoffs, and putting an end to life-long careers, along with all of the psychological and social stability that went with them. Such downsizing and deregulation also creates derivative dependency based on the constant disaggregation of assets made possible by deregulation, which are then reassembled in (partially) new configurations. Therefore, whereas in the past, industry and the market attempted to build:

tightly integrated commoditie[s] [...] financial engineering play[s] this process in reverse, disassembling a commodity [or company] into its constituent and variable elements and dispersing these attributes to be bundled together with elements of other commodities [or companies] [...] Each of these moveable parts is reassembled by risk attributes so that they become worth more as derivatives than their individual commodities [...] (Martin, 2013: 89)

This re-combinatory logic is also visible in various aspects of The LEGO Movie, as for example in how the story was crafted from characters and scenarios borrowed from well-known cultural commodities such as TV shows, other movies and LEGO's own playsets, "bundled together" in a partially new configuration. In this regard, one might say that the film is constructed through the decentralized, derivative dynamics of culture that shift between storyworlds, while cherrypicking characters to be recombined in partially new scenarios.

But to connect the derivative dynamics of culture specifically to subject formation, that is, to the kind of subject needed, required or produced through this logic, I want to reference a somewhat unlikely source, namely The Daily Mash. In 2015, this "satirical website which publishes spoof articles", featured a piece entitled "LEGO "promoting unrealistic body image", which colourfully illustrates the point I would like to make here concerning subjectivity. ${ }^{7}$ In this humorous piece, a father complains that "LEGO is promoting an aesthetic standard that is simply not achievable for human beings", and further, that his "daughter spends all her time trying to make her body shorter and stockier, and her nose disappear". Again, while this is quite obviously a send-up of LEGO's power to mould children and their behaviour, Henry Jenkins has similarly argued that transmedia texts do "not simply disperse information" but rather provide sets of "roles and goals" through which readers, players, and/or viewers "enact 
aspects of the story through their everyday life" (Jenkins, 2007: point 9). When one adds to this Randy Martin's (2013: 85) argument that “derivatives are not essentially economic but feature in all manner of social relations", then derivative logic, as communicated through the market, industry, and their products, including instruments of credit as well as entertainment commodities, may well have serious effects for us as subjects.

While the impact of financialization may not incite children to restyle their hands to resemble "half-eaten Hula Hoops", as The Daily Mash (2015) claims, it does, with equal wit, mention children's heartbreak over their inability to "develop a circular growth onto which various hats and hairstyles can be clicked". To my mind, this last quip cleverly reverberates with the current economic order. This is to say, that the ability to click worker subjectivities on and off at will accords well with the lego-fication of corporations and public institutions, where I understand 'lego-fication' as the parceling out of work into temporary packages - bricks severed from any semblance of employee benefits, and from which workers must attempt to assemble a life. The trend to mass layoffs (such as LEGO's current move to make 1,400 employees redundant), constant restructuring (such as LEGO's decision to press "the resetbutton for the entire group" - see Monaghan, 2017), and the ensuing loss of job security, demands its compliment of lego-fied subjects who are interchangeable and, like minifigures, move from playset to playset, or from contract to contract, having given up on the notion of a sedimented professional calling.

Deleuze referred to this kind of subject as a 'dividual', constituted from "sub- and transindividual arrangements of intensities at the level of bodies-in-formation" (Anderson, 2010: 165). For Appadurai, this type of subjectivity comes into focus in our current "predatory" capitalist mode, wherein,

numbers are attached to consumer purchases, discrete interactions, credit, life-changes, [...] so as to make these parts of the individual combinable and customizable [...] to render moot or irrelevant the idea of the 'whole', classical individual. (Appadurai, 2016: 109-10)

The world depicted in The Lego Movie, and increasingly our own, is populated by such 'dividuals' whose information can be searched, combined and re-aggregated for profit, as legofied labourers move between jobs, taking on lego-fied work-packages that amount to a piece, or a brick, of what would formerly have been an entire job, performed in the past by an individual. This is why, like Emmet who checks the impulse to complain and replies "whoa, awesome!" to overpriced coffee ("that's 37 dollars"), we are encouraged to accept systemic contingency and failure, inflation, constant precarity, and the inability to achieve professional goals such as tenure that decades ago would have been the norm, while reveling in predictable popular culture outputs such as the film's academy award winning theme song, "Everything is Awesome!"

\section{Securitizing minifigures}

The notion of reframing disappointments - losing a job, precarity, inflation - as some form of opportunity or cause for celebration, is again, as applicable to The LEGO Movie as it is to our daily lives, wherein 'the happiness industries' that support this kind of optimism-in-the-face-ofadversity take on an ever-greater role (Davies, 2015). The happiness and self-actualization industries are also part of the current economic trend toward the responsibilization of the individual, whereby citizens are made increasingly responsible for their own economic health and mental welfare as the social safety net erodes apace. Together with cheap expendable 
labour, these ancillary feel-good industries help corporations to maximize profits while minimizing liability. And, all of these trends ultimately help to secure the operability of the state which itself is increasingly run like a business that 'makes deals' rather than governs. This is what Lightfoot and Lilley (2017: 538) have referred to as the stratified state, wherein "each fragment, each individualized neoliberal subject becomes responsible for the management of his or her own risks to (financial) security". So, while the protagonists of the film are supposedly securitized as labourers through their uniformity and adherence to the rules, they are also are compelled to labour through affective control strategies such as Taco Tuesdays, while following a self-help manual, presumably produced by Octan.

The opening scene of The LEGO Movie, wherein we find Emmet performing his morning ablutions while following a twenty-one step self-help manual entitled Instructions to fit in, have everybody like you, and always be happy, should then perhaps be understood as an ironic reading of the multibillion-dollar motivational industries that inform a good deal of global culture (Ehrenreich, 2009: 100). Emmet is coached to fit in, obey the rules and consume products he can ill afford while smiling, as he undergoes the transparent monetization and reformation of his psyche, ultimately making him an even more ideal, reliable corporate employee. And again, this reflects the real-world situation, wherein the self-help industries have supported, for example, the developments in corporate downsizings that occurred between 1981 and 2003, resulting in the growth of both the happiness and team-building industries as a remedy for deteriorating employment conditions. Hence, "just as layoffs were making a mockery of the team concept, employees were urged to find camaraderie and a sense of collective purpose at the micro level of the "team'” (Ehrenreich, 2009: 120). ${ }^{8}$ These developments are captured in Emmet's adherence to his manual's "uplifting" instructions for work and personal hygiene, and in the lyrics to the film's theme song that drum "everything is cool when you're part of a team!" into Emmet Brickowski's high-density, plastic head.

\section{Feel-good aesthetics for a downsized world}

Michael Hardt (1999) has described the various activities and products, such as those created by the self-help industries that feed corporate feel-good, as an "affective politics". These belong to or sustain "affective labor", which is immaterial "in the sense that its products are intangible: a feeling of ease, well-being, satisfaction, excitement, passion - even a sense of connectedness or community", as when one is "part of a team" (Hardt, 1999: 96). Affective capitalism, moreover, is channeled through the sensational, and characterized by sensorial products and services that help to distract attention from serious problems in the neoliberal order, while embracing precarious subjects with manufactured warmth and care, in order to secure more labour and mental resources. President Business' Taco Tuesdays and his promise of love in The LEGO Movie is a prime example of the kind of affective politics to which I refer. However, the presentation of this form of control through affect and affect-producing marketing is presented in such an overwhelmingly cynical way that, by the close of the film, Vitruvius openly admits that he, like President Business, simply made up his (and the film's) heart-warming message. As the venerated prophet explains, he did so "because the only thing anyone needs to be special is to believe that you can be", following which he promptly adds that he knows this message "sounds like a cat poster", and asks if that really matters if people believe in it.

Throughout this article, I have commented on The LEGO Movie's use of irony and here, the motivational cat poster suggests one particularly cynical genre of irony that invites a closer look, along with why audiences might be amused by it. David Foster Wallace has identified a 
form of exhausted, cynical, commercialized irony that he associates with television and American fiction of the 1990s, and which is arguably a direct consequence of the progressive financialization of our lives. This kind of irony also typifies The LEGO Movie, which has been described as a "90-minute ad" and a "film that was dreamed up by a bunch of marketing executives looking for product integration" (Pomerantz, 2014: para. 1). For Wallace (1993: $177,174)$, this kind of cultural production is a "way to make commercials resemble programs: [by having] programs start to resemble commercials," whereby "nostalgia is yoked to purchases of products" that for some, like AFOLs, are representative of "a lost era of genuine conviction". Of course, nostalgia is linked to the purchase of products through many details of The LEGO Movie, not the least of which being the CGI version of the "Classic Vintage Blue 1980 Something Space Guy", who sports a manufacturing flaw that people who were kids in the 1980 s enjoy remembering, namely a crack in the chin-strap of his helmet where the toy habitually broke. As I noted above, the film also employs nostalgia in its marked tendency to embrace fictions that are "already composed of fictionalized characters in highly ritualized narratives", yet another aspect of the kind of irony about which Wallace (1993: 153) wrote. Indeed, the film abounds in characters like Batman, Michelangelo the Teenage Mutant Ninja Turtle and so on, all of whom behave in predictable, "ritualized" fashion to be taken in by viewers "in an attitude of rapt, relaxed reception" (Wallace, 1993: 155), which again was part of ensuring the film's financial success.

This sort of commercial, postmodern irony, whereby "every joke and dramatic surge depends on involution" and every joke is an "in-joke within [an] in-joke", is indicative of the market's need to produce entertainment with mass appeal (Wallace 1993: 159). Given this last observation, it is little wonder that Entertainment Weekly movie critic Owen Gleiberman summed up the film's relationship to what he would anticipate from contemporary audiences, claiming that the film was "10 times more clever and smart and funny than it needed to be" (quoted in Pomerantz, 2014). To paraphrase: the critic's comment suggests that the producers of The LEGO Movie did not have to take as much trouble as they did in order to entertain, because viewers know how to understand the film's humour as a function of various forms of soft conditioning (entertainment, affect, nostalgia) as well as hard conditioning (deregulation, banking practice, government policy). Or, lulled into quietude though affect and entertainment, audiences accept and find funny their own precarity and financial difficulties, which in turn helps the LEGO Group to secure profits though a cinematic spoof of the company's own business model and the economic order to which it belongs. Importantly, moreover, Wallace (1993: 182) also notes that contemporary commercial irony has lost its critical bite, by failing to "exploit gaps between what's said and what's meant, between how things try to appear and how they really are", which is the mainstay of classic, critical irony. What contemporary irony, like that which informs The LEGO Movie, does exceedingly well however, is make itself "commercially and psychologically viable" through homogenizing, over-determined, massmarketed narrative conventions that capture and neutralize any protest or critique that might be awakened by genuine ironic unease entailed in contemplating semantic gaps and confusions (Wallace, 1993: 171, 173).

Furthermore, for Wallace, the disarming and profit-producing potential of recent pop culture entertainment is further assisted by prettiness, a minor aesthetic that absorbs viewers, and which he sees as the apotheosis televisual culture. ${ }^{9}$ Where The LEGO Movie is concerned, I would argue that a related, equally minor aesthetic holds sway, namely cuteness. This aesthetic has the power to cement emotive connections and was first explored by ethologist Konrad Lorenz in an essay entitled "Innate forms of experience" [Die angeborenen Formen möglicher Erfahrung], published in $1943 .{ }^{10}$ For Lorenz, cuteness, in the form of neotenous or 
babyish traits, acts as an innate releasing mechanism in adults that encourages caring instincts. More recent scholarship has explored cute aesthetics and their commercial appeal, as well as the political potential of cuteness to encourage affiliative tendencies and social engagement, invoking a state that renders the world unthreatening and playful, while fostering responsiveness, and quelling anxiety (see Dale et al., 2017: 5). Quite obviously, The LEGO Movie trades on cuteness, from its cubby, neotenous minifigures to the movie's motivational cat poster, which in turn brings to mind the endless forms of cute cat culture that have invaded our lives from viral cat videos on social media, to Princess Unikitty, the film's version of Hello Kitty. On the one hand then, the LEGO Group secures revenues through cuteness. On the other hand, cuteness has come to sugar-coat our daily lives, profitably triggering cuddly affects in self-regulating subjects, just like Emmet, who are caught up in the securitizing labour of constant self-improvement to meet company and state targets.

Cuteness, as related to Wallace's concept of contemporary irony, likewise co-opts resistance and remakes failed circumstances and subjectivities with adorable aesthetics. In doing this, cuteness acts as an affective wrap that insolates us as financialized, securitized subjects, inviting us to consume cute products as we witness the erosion of social safety nets and deal with increased precarity and insecurity in the work place. Therefore the film, as I read it, foregrounds links between finance and security in the form of the LEGO business model, as well as governance structures intended to regulate bodies, in an affective, ludic, and seemingly harmlessly cute fashion. As such, cuteness is part of the very aesthetic texture of The LEGO Movie, every bit as much as its cute, digitally mimicked amateur stop-motion animation.

And finally, it is worth noting that the cuteness of LEGO also inspires 'playbour', a term coined to describe the trend to 'gamifying' labour with things like Taco Tuesdays in order to convince workers that they're having fun, or cute cat posters that invite us to "hang in there" while dealing with stress and lowering our expectations for the good life (see TV Tropes Wiki, n.d.). Playbour also refers to work performed, most often free of charge, by fans, bloggers, and interactive media users who generate content for companies like LEGO. As one blogger pointed out, "the film's humour comes from jokes that can be done with LEGO Toys", ${ }^{11}$ and jokes that were made first by fans in amateur short films known as "brickfilms". The LEGO Movie therefore "incorporate[es] peripheral, many-to-many activities and practices within new products, [for] a commodified geography of LEGO play" which emerges when "work penetrates and commodifies play [and] divergent user practices are "harvested' and commercially used" (Lauwaert, 2009: 69). Indeed, the profit-generating potential of fan-produced content, such as the short animations to which the company was opposed until 1987 when the LEGO Group began officially sponsoring "brickfilms", and which LEGO now facilitates by marketing its own "Movie Maker Set", is key to understanding how fans produce cost-free creative content for the company, thereby securing the company's profitability and sustained growth.

\section{Conclusion}

In this article, I have attempted to interrogate the social substance of finance and security by addressing how a variety of issues that coalesce around this node have been popularized in one particular Hollywood film. By discussing The LEGO Movie and how it represents finance, security, surveillance, the circulation of money, and subjectivity, as opposed to purportedly more 'serious' objects of study, the article highlighted how popular media outputs have the potential to acclimatize broad segments of populations to the mechanisms and machinations involved in the close relationship between finance and security. 
Moreover, by analyzing a popular film, and particularly one which might seem an inconsequential entertainment, my goal was to show not only how finance and security are entangled, but also how they are entangled in the fabric of our daily lives, right down to the most playful of objects. Hence, the added value of this discussion is the various ways in which it highlights the importance and productivity of asking questions of and about the seemingly benign and trivial outputs of the popular culture industries. In the case of The LEGO Movie, for example, we might ask what it means that large audiences can accept and enjoy a film in which a narcissistic-psychopathic businessman and his henchmen, known simply as micromanagers, fill the typical bad-guy roles. What may we conclude when audiences, made up largely of children, can laugh at a sentimental comedy about a despotic corporation that specializes in surveillance equipment? So while this article admittedly occupies a rather odd niche in the literature on security and finance by discussing toys and movies rather than directly addressing real-world banking practices, or the surveillance industries and their reliance on data flows, I hope also to have shown the importance of interdisciplinary work where these issues are concerned, as well as the importance of taking a serious look at the non-serious.

\section{Notes}

1. In using the term 'financialization' I follow Randy Martin (2002: 9), who wrote that "financialization must refer to many different processes at once", including not just the global financial order but also "[h]ow individuals come to think about themselves, take stock of how they are doing and what they have accomplished, and how they know themselves to be moving forward through the measured paces of finance”. With 'securitization', I invoke Marieke de Goede (2010: 100), who reminds us that in addition to its strictly financial meaning, securitization can refer to "the discursive and political processes through which societal phenomena become understood and addressed as security issues".

2. A full film script for The LEGO Movie is available at:

<https://www.springfieldspringfield.co.uk/movie_script.php?movie=the-lego-movie>. Further quotations from the film are taken from this source.

3. De Goede (2010: 109) has identified three different ways to think the finance-security relation. The first is instrumental, whereby finance may be "deployed in the service of national security and sovereignty" or whereby the national security apparatus serves financial interests. The second is causal, whereby "the ability to engender business security" or insecurity is ascribed to financial instruments. The third way is to understand finance and security as being conceptually inseparable, such that their relationship cannot be fully defined as either instrumental or causal. By referring to her first definition here, I in no way intend to dismiss the inseparability of finance and security, as will be made clear throughout the rest of this article.

4. This tension is central to much of the available LEGO scholarship (e.g., Giddings, 2014: 245-50). See also BBC (2016) and CNN (2016).

5. By 'Derridean free play', I refer to Derrida's (1978: 279) notion of a kind play that would be free of "the concept of structure", a stabilizing centre, or "fundamental ground".

6. As one blogger has observed, "the key to the Lego block, [is] the simple, consistent interface. The shape of the block doesn't matter - every block has the same interface allowing them to be connected" and disconnected in profit-generating ways (ObjectSharp, 2012: n.p.).

7. For the site's mission statement, see here: <http://www.thedailymash.co.uk/about>. For the LEGO piece, see Daily Mash (2015). 
8. For more on these kinds of strategies in the work place, see Bolton and Houlihan (2009).

9. As Wallace (1993: 173) writes, on TV "everybody we seek to identify with for six hours a day is pretty, [ ... so] prettiness becomes a priority for us, [as] the pretty people on TV become all the more attractive, a cycle which is obviously great for TV". On cuteness as a minor aesthetic, see Ngai (2012: 59-73).

10. For more on this, see Bolton and Houlihan (2009), Goggin (2012, 2016), and Kücklich (2005).

11. Notably, much of the creative content of The LEGO Movie was produced by fans for various company-sponsored contests (see The LEGO Movie: Fan Made Films, 2014). Moreover, as the term AFOL [Adult Fan of LEGO] implies, children become adult fans who also purchase toys like LEGO. This aspect of my argument is related to Scott Rettberg's (2008: 33) discussion of how World of Warcraft prepares children for the labour market, educating players in a range of behaviours and skills specific to conducting business in an economy controlled by corporations.

\section{References}

Amicelle, A. (2011) Towards a ‘new' political anatomy of financial surveillance. Security Dialogue, 42(2): 161-77.

Amoore, L. (2011) Data derivatives: On the emergence of a security risk calculus for our times. Theory, Culture \& Society, 28(6): 24-43.

Amoore, L. and de Goede, M. (eds.) (2008) Risk and the War on Terror. London: Routledge.

Anderson, B. (2010) Modulating the excess of affect. In: Gregg, M. and. Seigworth, G. (eds.) The Affect Theory Reader. Durham, NC: Duke University Press, 161-86.

Appadurai, A. (2016) Banking on Words: The Failure of Language in the Age of Derivative Finance. Chicago, IL: University of Chicago Press.

BBC (2016) Lego changes bulk buy policy after Ai Weiwei backlash. BBC News [Online], 13 January. Available at: <http://www.bbc.com/news/world-35299069>. Accessed 29 November 2017.

Bolton, S.C. and Houlihan, M. (2009) Are we having fun yet? A consideration of workplace fun and engagement. Employee Relations, 31(6): 556-68.

Boy, N. (2015) Sovereign safety. Security Dialogue, 46(6): 530-47.

CNN (2016) Everything awesome again? LEGO changes guidelines for bulk orders. CNN [Online], 14 January. Available at: <http://edition.cnn.com/style/article/lego-changes-guidelines-for-bulkorders/index.html>. Accessed 1 December 2017.

Daily Mash, The (2015) LEGO 'promoting unrealistic body image'. The Daily Mash [Online], 18 June. Available at: <http://www.thedailymash.co.uk/news/society/lego-promoting-unrealistic-bodyimage-2015061899397>. Accessed 28 November 2017.

Dale, J.P. et al. (2017) The Aesthetics and Affects of Cuteness. London: Routledge.

Davies, W. (2015) The Happiness Industry: How the Government and Big Business Sold Us Well-Being. London: Verso.

de Goede, M. (2010) Financial security. In: Burgess, J.P. (ed.) The Routledge Handbook of New Security Studies. London: Routledge, 100-109.

Derrida, J. (1978) Structure, sign, and play in the discourse of the human sciences. In: Writing and Difference. Chicago, IL: University of Chicago Press, 278-95.

Ehrenreich, B. (2009) Smile or Die: How Positive Thinking Fooled America and the World. London: Granta.

Giddings, S. (2014) Bright bricks, dark play: On the impossibility of studying LEGO. In: Wolf, M.J.P. (ed.) LEGO Studies: Examining the Building Blocks of a Transmedial Phenomenon. London: Routledge, 241-68. 
Goggin, J. (2012) Regulating virtual subjects: Finance, fun and games. Journal of Cultural Economy, 5(4): 441-56.

Goggin, J. (2016) Playbour, farming and leisure. ephemera: theory and politics in organization, 11(4): 357-68.

Hardt, M. (1999) Affective labor. Boundary 2, 26(2): 89-100.

Harvey, D. (1991) Time-space compression and the postmodern condition. In: The Condition of Postmodernity. Oxford: Blackwell, 284-308.

Jameson, F. (1991) Postmodernism, or, The Cultural Logic of Late Capitalism. Durham NC: Duke University Press.

Jenkins, H. (2007) Transmedia storytelling 101. HenryJenkins.org, 22 March. Available at: <http://henryjenkins.org/2007/03/transmedia_storytelling_101.html>. Accessed 21 November 2017.

Klein, N. (2007) The Shock Doctrine: The Rise of Disaster Capitalism. London: Penguin.

Kücklich, J. (2005) Precarious playbour: Modders and the digital games industry. The Fibreculture Journal, 5: FCJ-025. Available at: <http://five.fibreculturejournal.org/fcj-025-precarious-playbourmodders-and-the-digital-games-industry/>. Accessed 2 March 2016.

Langley, P. (2010) The ethical investor and embodied economies. In: Abdelal, R., Blyth, M. and Parsons, C. (eds.) Constructing the International Economy. Ithaca, NY: Cornell University Press, 211-27.

Langley, P. (2015) Liquidity Lost: The Governance of the Global Financial Crisis. Oxford: Oxford University Press.

Lauwaert, M. (2009) The Place of Play: Toys and Digital Cultures. Amsterdam: Amsterdam University Press.

The LEGO Movie (2014) Dir. Phil Lord and Christopher Miller, Warner Bros.

The LEGO Movie: Fan Made Films (2014) Official Warner Bros. UK YouTube Channel. Available at: <https://www.youtube.com/watch?v=XSSZJxDsjew>. Accessed 28 November 2017.

Lightfoot, G. and Lilley, S. (2017) Organising destruction: A derivative logic? Organization, 24(4): 53448.

Lobo-Guerrero, L. (2011) Insuring Security: Biopolitics, Security and Risk. London: Routledge.

Lorenz, K. (1943) Die angeborenen Formen möglichen Erfahrung. Zeitschrift für Tierpsychologie, 5: 245-409.

Martin, R. (2002) Financialization of Daily Life. Philadelphia, PA: Temple University Press.

Martin, R. (2007) An Empire of Indifference: American War and the Financial Logic of Risk Management. Durham, NC: Duke University Press.

Martin, R. (2013) After economy? Social logics of the derivative. Social Text, 31(1): 83-106.

Monaghan, A. (2017) Lego to axe 1,400 jobs. The Guardian [Online], 5 September. Available at: <https://www.theguardian.com/business/2017/sep/05/lego-to-axe-1400-jobs>. Accessed 28 November 2017.

Ngai, S. (2012) Our Aesthetic Categories: Zany, Cute, Interesting. Cambridge, MA: Harvard University Press.

ObjectSharp (2012) The legofication of business. ObjectSharp Blog [Online], 13 August. Available at: <http://blogs.objectsharp.com/post/2012/08/13/The-Legofication-Of-Business.aspx>. Accessed 29 November 2017.

Pomerantz, D. (2014) What Hollywood can learn from the success of The LEGO Movie. Forbes [Online], 11 February. Available at: <https://www.forbes.com/sites/dorothypomerantz/2014/02/11/whathollywood-can-learn-from-the-success-of-the-lego-movie/\#533873563f05>. Accessed 1 December 2017.

Rettberg, S. (2008) Corporate ideology in World of Warcraft. In: Corneliussen, H. and Rettberg, J.W. (eds.) Digital Culture, Play, and Identity: A World of Warcraft Reader. Boston, MA: MIT Press, 19-39. 
Sanders, J. (2006) Adaptation and Appropriation. London: Routledge.

Simmel, G. (2004) The Philosophy of Money. London: Routledge.

Simons, J.W. (2015) Opinion: Why LEGO is ruining our kids' imaginations. CNN [Online], 1 December. Available at: <http://edition.cnn.com/2014/12/01/opinion/lego-imagination-opinion/index.html>. Accessed 2 March 2016.

Taylor, M.C. (2004) Confidence Games: Money and Markets in a World without Redemption. Chicago, IL: University of Chicago Press.

TV Tropes Wiki (n.d.) Western animation/The LEGO Movie. TV Tropes Wiki [Online]. Available at: <http://tvtropes.org/pmwiki/pmwiki.php/WesternAnimation/TheLEGOMovie>. Accessed 1 December 2017.

Vogl, J. (2017) The Ascendancy of Finance. Cambridge: Polity.

Wallace, D.F. (1993) E unibus pluram: Television and U.S. fiction. Review of Contemporary Fiction, 13(2): 151-94. 